\title{
POLICY CORNER
}

\section{Past Fiscal Adjustments: Lessons from Failures and Successes}

\section{PAOLO MAURO and MAURICIO VILLAFUERTE*}

This paper analyzes large fiscal adjustment plans, defined on the basis of the envisaged reduction in the public debt or deficit, and it compares ex ante plans with ex post outcomes. The motivation for this novel approach is two-fold. First, useful lessons can be drawn not only from successes, but also from failures to meet policy objectives. Second, by taking into account whether observed outcomes stemmed from intended policies or unexpected developments, this paper sheds new light on some of the findings obtained by studies that had relied on a purely ex post approach. The evidence is based on in-depth individual country case studies for each of the 67 countries and on a systematic, crosscountry statistical analysis of all fiscal adjustment plans presented by all European Union countries during the past two decades. [JEL H60, H62, H63] IMF Economic Review (2013) 61, 379-404. doi:10.1057/imfer.2012.12; published online 9 October 2012

\section{W} ith the global financial and economic crisis that started in 2007-08, the state of the public finances in advanced economies has experienced its most pronounced worsening since the Second World War. As a result, government debts in the G7 countries are now higher than they

*Both authors are in a Fiscal Operations Division in the IMF's Fiscal Affairs Department. Paolo Mauro is Assistant Director and Division Chief. Mauricio Villafuerte is Deputy Division Chief. This paper draws on the book Chipping Away at Public Debt-Sources of Failure and Keys to Success in Fiscal Adjustment, edited by P. Mauro (Wiley, 2011). 
Figure 1. General Government Debt in G7 Economies, 1950-2010 (In percent of GDP)
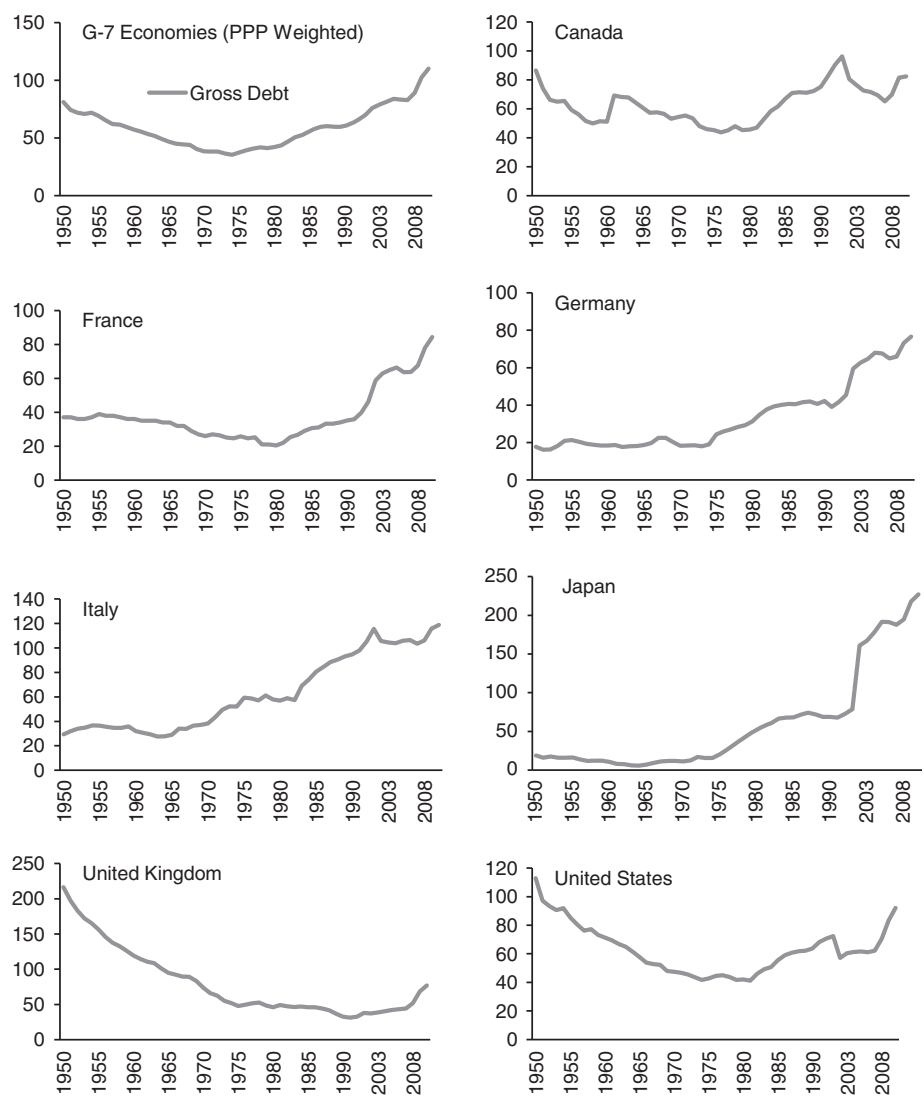

Source: Abbas and others (2011).

Note: G7 average is weighted by gross domestic product at purchasing power parity.

were in the early 1950s, that is, in the immediate aftermath of the Second World War (Figure 1; see also Abbas and others, 2011). ${ }^{1}$ These fiscal challenges are exacerbated by preexisting spending pressures in aging-related areas (pensions and, especially, health care). With rising concerns about fiscal policy and public debt sustainability in many advanced economies and high sovereign bond spreads in several of them, there is now greater consensus on the need to design and begin to implement fiscal adjustment plans for those countries. ${ }^{2}$ Fiscal adjustment will be a defining policy challenge for the next decade.

${ }^{1}$ The IMF's Fiscal Monitor (issued twice a year) reports on developments in fiscal variables and estimates fiscal adjustment needs for a large sample of countries.

${ }^{2}$ By "fiscal adjustment" we mean an improvement in the fiscal balance as a share of GDP (and, ultimately, a reduction in the public debt-to-GDP ratio) obtained by increasing revenues or cutting expenditures. 
Large fiscal adjustments have attracted much interest in previous analytical studies. However, previous efforts focused on ex post successes, identifying successful fiscal adjustment episodes on the basis of the largest observed improvements in the government debt or the fiscal balance - an approach followed for both advanced economies (for example, Alesina and Perotti, 1995; Alesina and Ardagna, 1998, 2009; and von Hagen and others, 2001), and broader samples of countries (for example, Giavazzi and others, 2000; Gupta and others, 2005). That traditional approach asked important questionssuch as whether fiscal adjustments are longer lasting and more successful when they rely on expenditure cuts rather than on tax hikes - and yielded useful information. Nevertheless, important pieces of the puzzle are still missing.

This paper, and the book from which it is derived, takes a novel approach: it analyzes large fiscal adjustment plans, defined on the basis of the size of the envisaged reduction in the public debt or deficit, and it compares ex ante plans with ex post outcomes. The motivation for, and value added of, this approach is two-fold. First, useful lessons can be drawn not only from successes, but also from failures. Second, it is important to understand whether observed outcomes stem from intended policies or unexpected developments. Indeed, the results in this paper will shed new light on some of the findings that had been obtained through the traditional approach, whose samples of interest had been selected based on outcomes.

Specifically, the evidence provided in the book and summarized in this paper is drawn from in-depth individual country case studies for each of the G7 countries during the past few decades and a systematic statistical analysis of all the (rolling) three-year plans presented by each European Union member country each year between 1991 and 2007. The objective is to inform the public debate over how to ensure successful fiscal adjustment in the period ahead, through systematic analysis of past adjustment plans and their outcomes. Although today's circumstances may be different from the past, history can offer lessons in terms of pitfalls to avoid and successes to be replicated.

The key, broad finding of this paper is that deviations of outcomes from plans are often large, and stem primarily from macroeconomic shocksespecially economic growth that differs from projections embedded in the plans. An ensuing policy lesson is that it is important to spell out in advance policies to respond to such shocks. Additional findings are presented in the remainder of the paper, which is organized as follows. Section I outlines the analytical framework, explains how the plans to be analyzed in the case studies on each of the G7 countries were selected (using solely ex ante criteria), and provides a concise summary of some of the key findings of each case study that seem to be relevant for other countries as well. Section II puts together the main findings along various dimensions, drawing from both the G7 country case studies and the cross-country statistical analysis on the EU sample. Section III provides a somewhat more detailed presentation of the cross-country regression analysis on the EU sample and its main results. Section IV draws lessons for the design and implementation of fiscal adjustment plans. 


\section{Analytical Framework: An Ex Ante Perspective}

\section{Methodology}

From an analytical perspective, this paper departs from previous literature by selecting its sample of interest through an ex ante criterion: large fiscal adjustment plans on the basis of the magnitude of envisaged reductions in debts and deficits. The paper thus shifts the focus of empirical analysis to the design of large fiscal adjustment plans, and the comparison of ex ante plans vs. ex post outcomes. More specifically, it looks at deviations from targets in revenues or expenditures and the factors underlying such deviations - including deviations of macroeconomic variables such as economic growth and interest rates from assumptions under the plans. The analysis is applied to both individual country cases and a cross-country statistical sample.

Before turning to the main analysis, a few words on methodological aspects-including what we do not do, as well as differences from related literature. First, we do not seek to assess the impact of fiscal adjustment on economic growth. A recent contribution to, and thorough summary of, that large literature is in Chapter 3 of October 2010 World Economic Outlook. Second, we do not analyze the effects of the external environment, monetary policy, or the exchange rate on the degree of implementation of the fiscal adjustment plans. The reason is that we focus on deviations of fiscal outcomes from initial plans. External factors and the likely monetary policy stance would be taken into account by the authorities when drawing up their fiscal adjustment plans. Moreover, to the extent that such factors turn out different from assumptions in the plans, the main channel through which they affect fiscal outcomes is via surprises in economic growth and, to a lesser extent, interest rates, both of which we take into account explicitly.

\section{Individual Case Studies}

These focus on each of the G7 countries (Canada, France, Germany, Italy, Japan, the United Kingdom, and the United States). The sample size and its composition were selected on various grounds: (i) the fact that the need for fiscal adjustment is currently more acute in advanced economies; (ii) the availability of at least two large medium-term fiscal adjustment plans, with a reasonable degree of specificity, available to the public, and with a horizon of at least three years; and (iii) the desire to provide details on the motivation for fiscal adjustment, the constraints faced by policymakers, and the realworld choices they had to make given the information that was available to them at the time. The specific ex ante consolidation attempts in each country were selected based on the large size of planned adjustment, formal and public commitment to adjust, detailed formulation, and medium-term perspective.

The choice of adjustment plans for a given country was relatively easy in some cases (for example, Canada, where only two medium-term plans 
were presented in recent decades) but required more elaborate criteria in others. For instance, for Germany, where medium-term fiscal adjustment plans have long been prepared each year (on a rolling basis), the four most ambitious plans were selected (on a purely ex ante basis) by the targeted improvement in the cyclically adjusted primary balance (computed using only real-time data that would have been available to contemporaries). In the case of Italy, where the public debt has been chronically high and medium-term fiscal adjustment plans have been published every year, but governments have been short-lived, the most important and ambitious fiscal adjustment plan (to meet the Maastricht criteria for euro entry) and the only plan designed and fully implemented by the same government were looked at.

In what follows, we provide a few key facts distilled from the case studies, highlighting those that seem to provide insights whose significance applies beyond the specific circumstances of the country in question. Table 1 summarizes the individual plans analyzed and their main features.

\section{Canada}

From an ex post perspective, Canada is ultimately the most successful case among the G7, going from the second-largest net debt-to-GDP ratio in the 1970 s to the lowest one beginning in the late 1990s. It is also a relatively simple case, as there were only two prominent fiscal adjustment plans, which relied on contrasting approaches, yielding substantially different results. The first attempt (1985-91) was relatively unambitious, as it sought to reduce the overall deficit by $3 \frac{1}{2}$ percent of GDP over six years and would not, even if fully implemented, reverse the rise in the debt-to-GDP ratio. The plan consisted mainly of across-the-board cuts and freezes. The second attempt (1994-97) was far more ambitious, seeking to reduce the overall deficit by 3 percent of GDP over three years. This plan involved a major restructuring of spending, including reforms of unemployment insurance, transfers to provinces, and pensions. In the event, both plans attained their intended objectives, but the second plan stands out in accomplishing a durable turnaround in the debt dynamics. Most important, the study reports that, based on surveys, the public's attitudes were much more favorable to fiscal adjustment prior to the launch of the plan of the 1990s than was the case in the 1980s, and that the government carefully explained the rationale for the adjustment and its composition to the general public.

\section{France}

The case study begins with early plans not set in multiyear frameworks (Plan Barre, 1976-77; Virage de la Rigueur, 1982-84). These were essentially austerity packages aimed at curbing inflation and current account deficits, through a combination of tax hikes and spending curbs. They were relatively effective in containing aggregate demand, but their impact was short-lived. More formal, multiyear planning really begins with the drive to meet the Maastricht criteria, especially the 1994-97 plan. Three-year plans were 


Objectives/Design

Comments/Outcome

\begin{tabular}{ll}
\hline Country & Adjustment Plan \\
\hline Canada & $1985-91$ \\
& $1994-97$ \\
France & \\
& Plan Barre, 1976-77 \\
& Virage de la Rigueur, \\
& 1982-84 \\
& 1994-97 Plan aimed at \\
meeting the \\
Maastricht criteria \\
2003-07 Consolidation \\
under the Excessive \\
Deficit Procedure
\end{tabular}

- Reduce overall deficit by $3 \frac{1}{2}$ percent of GDP over six years.

- Across-the-board cuts and freezes.

- Reduce overall deficit by 3 percent of GDP over three years.

- Major restructuring of spending, including reforms of unemployment insurance, transfers to provinces, and pensions.

- Austerity packages to curb inflation and current account deficit.

- Not set in multiyear frameworks.

- Combination of tax hikes and spending curbs.

- Reforms in 1982-84

- Introduced multiyear framework

- Quantitative objectives aimed at meeting Maastricht criteria

- Fiscal adjustment focused on expenditure control; revenue-toGDP ratios targeted to remain stable.

- Legally binding zero real growth rule for central government spending; health and pension reforms.

Germany

1976-79 Plan

1981-85 Plan

1991-95 Plan
- Cut deficit by $2 \frac{3}{4}$ percent of GDP.

- Back-loaded; focus on expenditures (generalized cuts; cuts in labor market expenditures; wage restraint).

- Cut deficit by $1 \frac{11 / 4}{4}$ percent of GDP.

- Front-loaded expenditure cuts (reduction in entitlement and wage bills).

- Cut deficit by $1 \frac{1}{2}$ percent of GDP while minimizing tax increases needed to finance unification.

- Mainly expenditure-based (defense, social spending). Revenue package from 1990 plus VAT rate hike.
Overall deficit objectives met, but not

sufficiently ambitious to halt the rise in debt.

Successfully met objectives and attained long-lasting reversal of debt dynamics.

Effective in reducing deficits and containing aggregate demand, but impact short-lived.

Met Maastricht criteria, partly through last-minute revenue measures. Difficulties in controlling expenditures.

Some expenditure slippages, partly offset by one-off revenues.

Weak economic growth led government priority to shift from fiscal adjustment to stimulus.

Largely successful.

Did not meet objectives. 
2003-07 Plan

Italy

1994 Economic and Financial Program Document (EFPD) for 1994-97

2002 EFPD for 2002-05

Japan

\section{7-Fiscal Structural} Reform Act

2002- Medium-Term Fiscal Adjustment Plans. (Two subperiods: 2002- and 2006-.

United

Kingdom

Howe's 1980 MediumTerm Financial Strategy

(FY1980-FY1983)

Lawson's 1984 Budget (FY1984-FY1988)
- Cut deficit together with "Agenda 2010" structural reforms (labor market, pensions).

- Back-loaded. All on expenditure side: reducing unemployment insurance, transfers to pension system, firing benefits, and subsidies.

- Reduce the debt-to-GDP ratio beginning in 1996.

- Strong interest in joining EMU. Initial plan did not aim at meeting Maastricht criterion of 3 percent deficit, but objectives made more ambitious in mid-course.

- Planned limited improvement in fiscal balance (by 1 percent of GDP), together with a 2 percent of GDP reduction in the revenue ratio, thus implying the need for a 3 percent of GDP expenditure cut.

- Reduce deficit to 3 percent of GDP by FY2003.

- No revenue-enhancing measures announced. Future policy decisions needed to achieve targets.

- Aim for primary surplus by early 2010 s

- Introduced five-year rolling frameworks.

- Three-year expenditure ceilings on initial budgets by major policy area introduced in FY2006.

- No revenue-enhancing measures announced. Future policy decisions needed to achieve targets.

- Curb government borrowing to rein in the money supply and inflation.

- Envisaged $5 \frac{1}{2}$ percent of GDP cut in the deficit, through lower spending and an expected rise in oil revenues.

- Rebalance the tax burden from direct to indirect taxes and reduce marginal tax rates.

- Shrink the State (Thatcher government agenda).

- Reduction in public sector manpower.
Largely successful. Higher-than-expected costs of labor market reforms. Increase in VAT made it possible to meet objectives while reducing the tax burden on labor.

Attained lasting reduction in debt-toGDP ratio, albeit at high levels.

Maastricht criterion met through lastminute efforts.

Revenue ratio remained unchanged. Large expenditure and fiscal balance overruns.

Immediately derailed by Asian crisis and domestic banking crisis.

Partially successful in the initial stages.

Ultimately derailed by the global crisis

Expenditure overruns in social security, public wages, and support to public enterprises.

Expenditure cuts beyond what was envisaged. Privatization of large public enterprises. 


\begin{tabular}{|c|c|c|c|}
\hline Country & Adjustment Plan & Objectives/Design & Comments/Outcome \\
\hline \multirow{5}{*}{ United States } & $\begin{array}{l}\text { Clarke's November } 1993 \\
\text { Budget (FY1994- } \\
\text { FY1998) }\end{array}$ & $\begin{array}{l}\text { - Eliminate the } 8 \text { percent of GDP deficit by } 1998 . \\
\text { - Increases in national insurance contribution rate and excises, } \\
\text { broadening of the VAT base. Freezes on running costs combined } \\
\text { with zero-based budgeting "fundamental expenditure reviews." }\end{array}$ & $\begin{array}{l}\text { Delivered a steady reduction in the fiscal } \\
\text { deficit. }\end{array}$ \\
\hline & $\begin{array}{l}\text { Darling's } 2007 \text { Pre- } \\
\text { Budget Report and } \\
\text { Comprehensive } \\
\text { Spending Review } \\
\text { (FY2008-FY2012) }\end{array}$ & $\begin{array}{l}\text { - Planned modest reduction in the deficit, by reducing the growth of } \\
\text { spending. }\end{array}$ & $\begin{array}{l}\text { Derailed by global crisis: revenue } \\
\text { underperformance, expenditure } \\
\text { overruns, capital injections to banks. }\end{array}$ \\
\hline & $\begin{array}{l}1985 \text { Gramm-Rudman- } \\
\text { Hollings (Balanced } \\
\text { Budget and } \\
\text { Emergency Deficit } \\
\text { Control Act) }\end{array}$ & $\begin{array}{l}\text { President to submit budgets consistent with GRH targets each } \\
\text { year and balanced budget by } 1991 \text {. } \\
\text { - If legislated policy was projected to result in higher deficits, } \\
\text { automatic "sequestration" with spending cuts would apply. }\end{array}$ & $\begin{array}{l}\text { Did not achieve targets but deficit would } \\
\text { have been larger in absence of GRH. }\end{array}$ \\
\hline & $\begin{array}{l}\text { OBRA-1990 (Omnibus } \\
\text { Budget } \\
\text { Reconciliation Act) }\end{array}$ & $\begin{array}{l}\text { - Reduce deficit by cumulative U.S. } \$ 500 \text { billion (equivalent to } 8.5 \\
\text { percent of } 1991 \text { GDP) in 1991-95. } \\
\text { - Introduced discretionary spending caps and pay-as-you-go } \\
\text { (PAYGO) mechanism. Included some tax increases. }\end{array}$ & $\begin{array}{l}\text { Unable to restrain the unexpected growth } \\
\text { in spending for entitlement programs } \\
\text { (notably, Medicare and Medicaid). }\end{array}$ \\
\hline & OBRA-1993 & $\begin{array}{l}\text { Reduce the deficit by } 13 / 4 \text { percent of GDP, relative to the no- } \\
\text { policy-change baseline, by } 1998 \text {. } \\
\text { PAYGO continued and discretionary spending caps extended, } \\
\text { with five-year nominal spending freeze. Some tax increases and } \\
\text { measures to close loopholes. }\end{array}$ & $\begin{array}{l}\text { Deficit reduction well in excess of targets, } \\
\text { with stronger-than-expected economic } \\
\text { growth and revenues, but also effective } \\
\text { spending caps. }\end{array}$ \\
\hline
\end{tabular}


subsequently prepared every year as part of France's commitments vis-à-vis the European Union. Among them, the 2003-07 plan is analyzed in detail, as it envisaged a sizable consolidation under the Excessive Deficit Procedure. Two results stand out from this case study. First, difficulties in controlling expenditures: ultimately, the Maastricht criteria (first plan) and the commitments under the EDP (second plan) were met partly through last-minute revenue measures. Second, gradual improvements in the ability to control expenditures were associated with increasingly legally binding targets for spending.

\section{Germany}

Among the many plans put forward by Germany over the years, the case study analyzes in depth the four plans that, on an ex ante basis, targeted the largest improvements in the structural fiscal balance. Several characteristics distinguish the more successful (ex post) plans of the 1980s (1981-85) and 2000s (2003-07) from the less successful plans of the 1970s (1976-79) and 1990s (1991-95): first, strategic reforms that reflected a change in the view on the appropriate role of the state; second, accompanying reforms beyond the fiscal area (notably, labor market reforms in the 2000s); and third, greater support of the need for fiscal consolidation among the general public.

\section{Italy}

The case study on Italy leverages the fact that (rolling) three-year plans have been prepared annually over the past couple of decades. By analyzing all the plans and their ex post outcomes, it finds that a steady source of slippages was the "base effect," that is, upward revisions to the initial deficit data, typically emerging only a few months into the implementation of each given adjustment plan. The study then delves into more detailed analysis of two prominent plans, as follows. First, the 1994-97 plan, motivated by the drive to enter the euro. This plan met the 3 percent deficit Maastricht criterion (partly through last-minute efforts, particularly on the revenue side) and attained a reasonably-lasting reduction in the debt-to-GDP ratio, albeit at high levels. Second, the only plan that was designed and fully implemented under one government (2002-05). This plan envisaged an improvement in the fiscal balance by 1 percent of GDP, together with a 2 percent of GDP reduction in the revenue ratio, thus implying the need for a 3 percent of GDP expenditure cut. In the event, the revenue ratio remained unchanged and sizable overruns took place on both expenditures and the fiscal balance. The takeaway from this second plan is that government stability in itself is no guarantee that fiscal objectives will be achieved.

\section{Japan}

In the case of Japan, formal medium-term planning is a relatively recent phenomenon, and only two plans (beginning in 1997 and 2002, respectively) 
were identified with a sufficient degree of specificity, for this study's purpose. In both instances, the main findings relate to the powerful adverse impact of negative surprises in economic growth, with both plans going quickly offtrack as a result of unexpected economic downturns. Another result relates to difficulties in attaining envisaged increases in revenues when the plans leave the actual revenue measures to be spelled out at a later stage.

\section{United Kingdom}

Beginning in the 1980s, each incoming Chancellor of the Exchequer presented a four-year plan, and the case study analyzes those that envisaged a sizable (ex ante) improvement in the fiscal balance (Howe, FY1980FY1983; Lawson, FY1984-FY1988; Clarke, FY1994-FY1998; and Darling, FY2008-FY2012). Plans that involved reforms to the key drivers of cost in the public sector (social security, health, education-by function; payroll, transfers, subsidies to public enterprises - by economic classification) met or even improved upon their objectives. In contrast, excessive reliance on cuts to infrastructure or to local authorities eventually resulted in spending overruns, as the need to maintain infrastructure or provide basic services ultimately prevailed.

\section{United States}

Although the United States has not traditionally prepared formal mediumterm fiscal plans, the case study analyzes prominent initiatives aimed at keeping the fiscal variables in check: the 1985 Gramm-Rudman-Hollings Act and the 1990 and 1993 Omnibus Budget Reconciliation Acts. Key takeaways include the following. As in other countries, the powerful impact of economic growth is evident, especially in the major improvement in the state of the public finances associated with the boom of the 1990s. At the same time, the initiatives to keep expenditures in check played a helpful role in reducing the extent to which extra revenues resulted in additional spending. Indeed, as expenditure limits were gradually made more legally binding over the years, they became increasingly effective. This said, the comparison between Canada and the United States is especially revealing, because while these two countries experienced remarkably similar economic growth developmentsnotably, booms in the mid- and late 1990s, Canada undertook reforms that resulted in a long-lasting improvement in the debt and deficit, whereas the United States experienced a temporary improvement in the fiscal variables that was reversed in the 2000s.

\section{Cross-Country Statistical Analysis on EU Sample}

The case studies are complemented by a systematic cross-country statistical analysis of large fiscal adjustment plans. Again, the sample was selected on an ex ante basis. The set of countries consists of the members of the European Union, which have to produce fiscal adjustment plans as part of 
their obligations as EU members. Specifically, a comprehensive database was constructed consisting of all the three-year "convergence" or "stability and growth" programs produced by each European Union country every year over the past couple of decades. The complete database consists of 229 three-year plans for 25 countries, covering 1991-2007: the pre-1998 plans were gathered from various archival sources, entering the data from hard copies, whereas the post-1998 plans were drawn from an existing EU database.

As the time span of plans published in 2006 and later overlaps significantly with the global financial crisis - whose impact would unduly dominate and skew the results of any systematic statistical analysis of this type-we focus on the 178 plans published before end-2005. Starting from these and defining as "large planned fiscal adjustments" those that envisaged a cumulative adjustment in the headline fiscal balance of more than 1 percent of GDP in the following three years, we identified a total of 100 large fiscal adjustment plans. Finally, for each country, plans with more than two overlapping years were dropped, yielding our sample of 66 large planned headline balance improvements.

The plans include both fiscal variables (including revenues, primary and interest expenditures, fiscal balances, and the public debt, all at the general government level) and underlying macroeconomic assumptions (real and nominal GDP levels and growth rates, inflation, interest rates, and so on) for the next three years. More specifically, from each plan, we collected the estimates for year $t$ (the year of the plan's publication), reported outcomes for year $t-1$, and projections for years $t+1, t+2$, and $t+3$.

We also recovered plan information on cyclically adjusted balances for the plans for which it was available (about one-half of the plans), and supplemented that information with our own computations of the cyclically adjusted balance, which we undertook using "real-time" output gaps - that is, using only the information that would have been available to contemporary observers. We drew final ex post data for the same variables from the European Commission's annual macroeconomic (AMECO) database.

This rich data set permits a comparison of expectations and outcomes not only for the fiscal variables, but also for several macroeconomic variables that are relevant for fiscal outcomes. Thus, using real-time data, plan implementation errors and ratios (actual adjustment vs. planned adjustment) and their economic and political determinants were analyzed.

A few more technical points regarding two key steps involved in defining fiscal adjustment and tracking implementation:

1. Defining fiscal adjustment. We define the ex ante planned adjustment as the projected percentage point increase in the fiscal balance-to-GDP ratio between years $t$ and $t+3$ as reported in the year $t$ plan. The corresponding ex post adjustment is defined as the actual percentage point increase in the fiscal balance-to-GDP ratio between years $t$ and 
$t+3$ as reported in the final data (the 2009 AMECO vintage). In addition to the overall fiscal balance and its revenue and expenditure components, we also track the change in the cyclically adjusted primary balance, subdivided into cyclically adjusted revenues and primary expenditures.

2. Measuring implementation. We use two measures of plan implementation: (a) an implementation ratio which, for each plan, scales the actual observed three-year cumulative improvement in the fiscal balance-toGDP ratio to the corresponding planned improvement; and (b) an implementation error, which, for each plan, subtracts the planned threeyear cumulative improvement in the fiscal balance-to-GDP ratio from the corresponding actual improvement. Perfect implementation would be implied by an implementation ratio of 1 or, equivalently, an implementation error of zero. Of course, overperformance of plans (implementation ratio greater than 1 , or implementation errors greater than zero) is also feasible.

An advantage of using the implementation ratio is that it appropriately scales actual performance to the plan's fiscal adjustment ambition (planned improvement in the fiscal balance) and is thus comparable across plans in a nonregression framework, that is, where ambition is not otherwise controlled for. An advantage of using the implementation error is the ease of interpretation it affords in a regression framework, as its units are percentage points of GDP. We therefore use this measure in our formal regressions (see Section III), where ambition is appropriately controlled for.

\section{Key Findings: Sources of Failure and Keys to Success in Fiscal Adjustment}

This section begins by reporting information on the rationale for, and composition of, the fiscal adjustment envisaged under the sample of plans reviewed in this study. Such information provides context to the lessons that can be extracted from the plans' design and their implementation record.

\section{Rationale and Composition of Fiscal Adjustment}

The rationale behind fiscal adjustment plans changed over time. In the 1970s and early 1980s, many adjustment plans focused on reducing fiscal deficits as part of a comprehensive strategy aimed at tackling macroeconomic imbalances, such as rising inflation and external current account deficits. This includes plans in France, Germany, and the United Kingdom, which took place in the aftermath of the oil shocks of the 1970s and ensuing hikes in interest rates. Beginning in the mid-1980s, there was increased emphasis on keeping in check or reducing public debt levels. While refinancing was not a major source of concern among advanced economies during the period considered, in a few cases (for example, Canada in the 1990s, Italy in the run-up to EMU) rising interest costs and spreads relative to neighboring countries were a motivating factor. In European countries, the Maastricht 
Table 2. Planned Sources of Fiscal Adjustment in 66 EU Plans (In percentage of total number of plans in the sample)

\begin{tabular}{lccr}
\hline & \multicolumn{3}{c}{ Expenditure } \\
\cline { 2 - 3 } & Increase & Decrease & Total \\
\hline Revenue & 10 & 27 & 37 \\
Increase & 0 & 63 & 63 \\
Decrease & 10 & 90 & 100 \\
& & 90 & \\
\hline
\end{tabular}

Note: The table reports the percentage of large fiscal adjustment plans (within our sample of 66 plans in EU countries) that involved an increase (decrease) in revenues (expenditures), as indicated.

criteria, the Stability and Growth Pacts, and the Excessive Deficit Procedure provided a context for fiscal adjustment plans. In general terms, the vast majority of the plans we consider were preceded by high or rising public deficits or debts.

In terms of the composition of fiscal adjustment (expenditure-revenue measure mix) envisaged at the time of the formulation and announcement of the plans, the data reveal that most plans focused on spending cuts. This is not surprising, in view of the relatively large initial size of government, particularly in European countries. In the EU sample consisting of 66 plans, almost 90 percent of the plans envisaged that more than half of the adjustment would come from spending cuts (as shares of GDP). Moreover, almost two-thirds of the plans envisaged that revenues would be cut as a share of GDP, thus requiring cuts in expenditure ratios in excess of the total adjustment in the fiscal balance (see Table 2).

Also noteworthy is the fact that of the about 20 plans stipulating increases in the revenue-to-GDP ratio, only about 10 were grounded in wellspecified tax policy changes (such as rate increases or elimination of clearly identified tax exemptions); the rest mentioned improvements in revenue administration and tax compliance, efforts against tax evasion, or generic base-widening. Thus, less than one-sixth the large planned consolidations in our sample envisaged deliberate increases in revenue ratios grounded in well-specified measures.

This leads to an alternative perspective on large, revenue-based, fiscal adjustments that had been identified as such by the traditional strand of literature using ex post outcomes. For example, almost all of the episodes in Alesina and Ardagna (1998) feature an increase in revenues by at least 1 percentage point of GDP; and two-thirds of the observed fiscal effort in large consolidations identified by Alesina and Ardagna (2009) came from the revenue side.

How can one make sense of the different roles of revenues when contrasting ex ante vs. ex post based definitions of large fiscal adjustments? In their ex ante plan design, policymakers usually intended to rely on 
expenditure cuts rather than revenue increases (indeed, they often hoped to cut spending sufficiently to make room for tax cuts too) but, as we show below, the ex post composition of adjustment turned out different than expected.

The analysis of the main findings regarding the plans' implementation, and associated lessons, can be grouped in two dimensions: (1) the degree of implementation and underlying macroeconomic factors, and (2) political and institutional determinants of the implementation record.

\section{Implementation Record and Underlying Macroeconomic Factors}

The record in terms of implementation of fiscal adjustment was mixed. Some plans examined under the country cases were successful, like the 1994 97 one in Canada or the consolidation plan from the early-2000s in Germany (see last column of Table 1); some other plans met their targets but through last minute measures (for example, in Italy and France) or their impact was short-lived; and many plans did not meet their objectives because of various reasons, including slippages in implementing adjustment measures. An assessment based on the cross-country EU sample suggests that, on average, outcomes fell short of plans' original targets: the average annual planned improvement in the structural fiscal balance was equivalent to 1.7 percent of potential GDP (cumulative over the three years), whereas the outcome was a 0.9 percent improvement.

The extent to which plans' objectives were met is not correlated with the initial degree of ambition: higher planned adjustment was associated with higher actual adjustment by a factor of one (observations are scattered closely around the 45 degree line in Figure 2). Although causality cannot be inferred, the evidence is loosely suggestive that it is "OK to plan big," because ambitious plans do not necessarily seem to lead to greater deviations from objectives than is the case for more modest plans.

A detailed analysis of the revenue-expenditure mix in outcomes relative to plans finds that, in most of the case studies, expenditure cuts did not materialize to the extent initially envisaged; by contrast, revenues often turned out above expectations because of favorable cyclical macroeconomic developments, higher asset prices, or the introduction of (temporary) revenue measures to offset difficulties in implementing expenditure cuts. The cross-country statistical evidence confirms these findings: while plans envisaged cuts in the ratio of structural primary spending to potential GDP of 1.8 percent on average, actual cuts amounted to 0.3 percent. In contrast, revenues overperformed somewhat, partially offsetting the expenditure overruns (Table 3).

Deviations of economic growth (and other macroeconomic assumptions) from initial expectations were a key factor underlying success or failure of fiscal adjustment plans. It is worth noting that the macroeconomic assumptions embedded in the original plans were mostly in line with those of independent observers (such as Consensus Forecasts and the IMF's World 
Figure 2. European Union: Planned and Actual Adjustments, 1991-2007 (Percent of potential GDP)

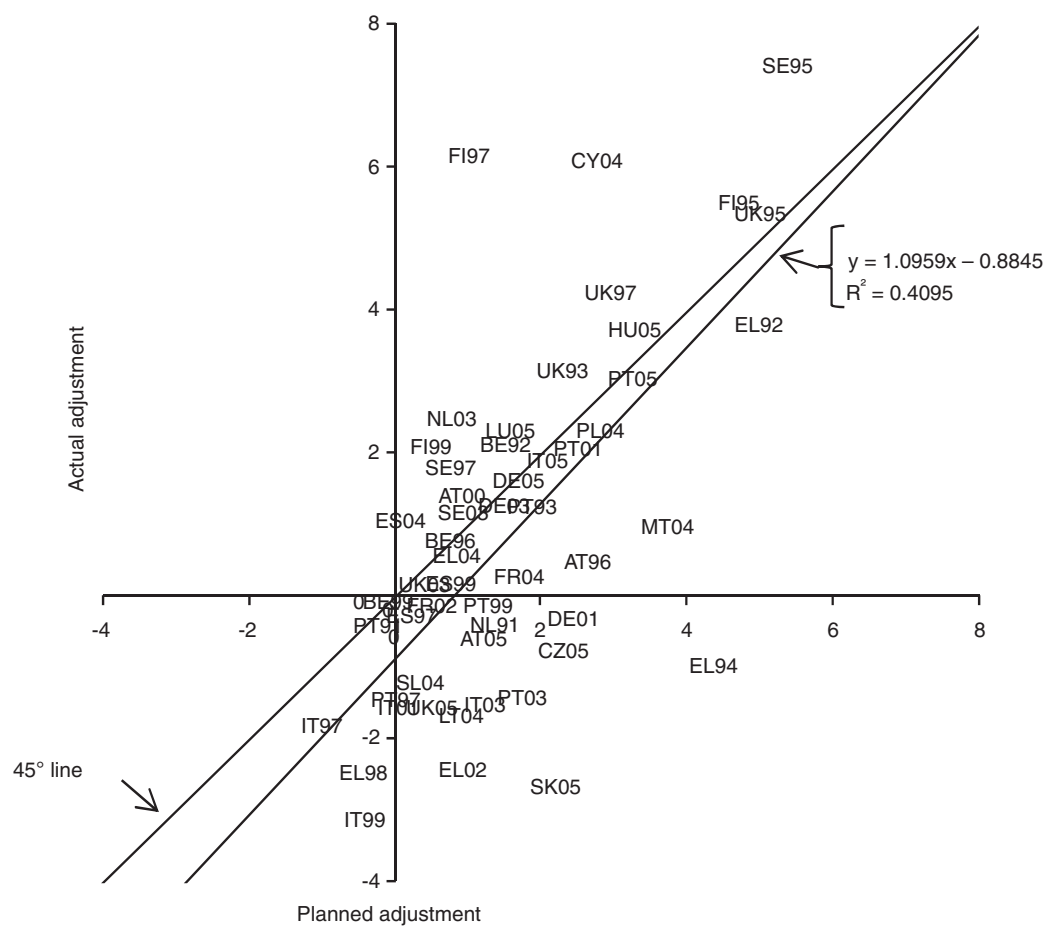

Source: EU countries' convergence plans and stability and growth plans; European Commission's Annual Macroeconomic Database (AMECO); and IMF staff estimates.

Note: Austria (AT), Belgium (BE), Cyprus (CY), Czech Republic (CZ), Finland (FI), France (FR), Germany (DE), Greece (EL), Hungary (HU), Italy (IT), Lithuania (LT), Luxembourg (LU), Malta (MT), Netherlands (NL), Portugal (PT), Slovak Republic (SK), Slovenia (SL), Sweden (SE), United Kingdom (U.K.). The two-digit numbers indicate the year when the plan was drawn up.

Economic Outlook). In other words, any surprises in economic growth and other macroeconomic variables were largely surprises for all observers. ${ }^{3}$ Some adjustment plans (for example, Germany in the 1970s; Japan) were derailed, almost immediately, by unexpected economic downturns. Lower growth had a direct negative impact on cyclical revenues (and, to a lesser extent, caused an increase in some expenditure items), thereby worsening the headline fiscal balance. In addition, it had an indirect impact by tilting the authorities' perception of the relative merits of fiscal consolidation vs. fiscal stimulus. Conversely, the success of some plans (for example, in the United States in the 1990s) was facilitated by higher-than-expected growth and asset

\footnotetext{
${ }^{3}$ Previous studies on this topic have only compared the assumptions underlying the authorities' plans with actual outcomes, rather than with forecasts by independent observers.
} 
Table 3. Actual vs. Planned Structural Fiscal Adjustment

(Percent of potential GDP; means reported, except for implementation ratios, which are medians)

\begin{tabular}{|c|c|c|c|c|}
\hline & $\triangle$ PLAN & $\triangle \mathrm{ACTUAL}$ & $\begin{array}{l}\text { Error }=\Delta \text { ACTUAL } \\
\text { Minus } \triangle \text { PLAN } \\
(0 \text { is Perfect } \\
\text { Implementation })\end{array}$ & $\begin{array}{c}\text { Median } \\
\text { Implementation } \\
\text { Ratio }=\Delta \text { ACTUAL } / \Delta \text { PLAN } \\
(1 \text { is Perfect Implementation })\end{array}$ \\
\hline Revenues & 0.1 & 1.0 & 0.9 & 0.5 \\
\hline Cyclical & 0.2 & 0.5 & 0.3 & 1.2 \\
\hline Structural & -0.1 & 0.5 & 0.6 & \\
\hline Expenditures & -2.3 & -1.0 & 1.3 & 0.4 \\
\hline Primary & -1.8 & -0.3 & 1.5 & 0.2 \\
\hline Interest & -0.5 & -0.6 & -0.1 & 1.0 \\
\hline $\begin{array}{l}\text { Structural primary } \\
\text { balance }\end{array}$ & 1.7 & 0.9 & -0.8 & 0.8 \\
\hline
\end{tabular}

Source: "Convergence" and "Stability and Growth" programs (plans); European Commission's AMECO database (outcomes).

Note: $\triangle \mathrm{PLAN}$ and $\triangle \mathrm{ACTUAL}$ refer to the planned and actual change in each item, in percent of potential GDP.

price developments. In the cross-country analysis, a one percentage point improvement in growth compared with expectations resulted, on average, in a $1 / 2$ percent of GDP strengthening in the headline fiscal balance.

The case studies reveal that fiscal adjustment plans were more likely to meet their objectives when they were grounded in structural reforms. This was evident in Germany both in the 1980s and 2000s, when structural reforms were introduced into the social welfare system to enhance its sustainability in light of changes in potential growth prospects in general and in labor markets in particular. The "Lawson adjustment" of the 1980s in the United Kingdom offers another relevant example, with significant expenditures cuts and privatization of public enterprises as part of Prime Minister Thatcher's redefinition of the role of the state. A similar dynamic was present in Canada in the mid-1990s, where a repositioning of the role of the state was supported by a comprehensive expenditure review. Those experiences stand in contrast with other plans in the same countries that eschewed reforms and failed to meet their targets.

\section{Fiscal Institutions and Political Factors}

The detailed case studies, which included a review of the budgetary and legal frameworks as well as the political dynamics behind the plans' motivations, design and implementation, allowed the identification of specific institutional and political factors that had a bearing in the success or failure of fiscal adjustment plans. 
In terms of features of fiscal institutions, the following aspects can be highlighted as influencing the degree of implementation of fiscal adjustment plans:

- Monitoring of fiscal outcomes and policy response to data revisions. The probability of meeting fiscal targets is enhanced by the timeliness and accuracy of systems in place to measure and monitor fiscal targets. For instance, properly determined starting points for a consolidation plan (for example, the previous year's fiscal deficit) facilitate the determination and achievement of future targets; alternatively, and to preserve their credibility, plans could explicitly include policy responses to any data revisions. Conversely, shortcomings in these areas can negatively affect adjustment plans. This was the case of Italy, where a significant portion of the deviations of outcomes from plans reflected upward revisions to the initial deficit, which were not compensated for through subsequent revisions to medium-term plans. In the cross-country analysis, upward revisions of deficits generally resulted in larger deficits at the end of the period, whereas downward revisions in the deficit were less likely to result in changes to the end-period deficit targets or outcomes.

- Binding medium-term limits. Although the presence of medium-term plans was one of the criteria for choosing the case studies reviewed, the extent to which they included binding limits on expenditures varied. As medium-term limits were made more legally binding, actual compliance with spending targets improved. This pattern was most noticeable in the United States in the 1990s, where constraints on discretionary expenditure allowed a more rapid improvement in the fiscal balance in the context of favorable growth and asset price developments. Other successful examples include the French 2003-07 fiscal adjustment plan that relied on legally binding real expenditure growth limits and the spending ceilings in the United Kingdom (which evolved over time with greater detail and fixity achieved at the cost of lower coverage of public expenditure).

- Contingency reserves. Some plans used contingency reserves to build in space to cope with potential adverse shocks, accelerate the adjustment, or create room for reducing the tax burden in the event that no adverse shocks materialized. Contingency reserves played a role in the extent to which fiscal adjustment targets were met in the United Kingdom and, to a lesser extent, in Canada.

- Coordination across levels of government. Although most of the adjustment plans studied were originally devised for the central government, several involved reductions in transfers to subnational governments or other public entities. The extent to which those entities undertook parallel fiscal consolidations was an important determinant of whether the general government balance improved (as in Canada) or challenges were encountered (France and the United Kingdom). In the latter cases there was a tendency to 
overestimate the share of the adjustment that could be imposed on local authorities or there were weak mechanisms in place to allow the central government to monitor and control local government expenditure.

- Fiscal rules. Although there is a fervent debate in the economics profession and among policymakers on the pros and cons of fiscal rules (that is, defined as a permanent constraint on fiscal policy through simple numerical limits on budgetary aggregates), it would seem reasonable to expect the presence of strong fiscal rules to help consolidation plans meet their objectives. Tentative evidence supporting this hypothesis was found in the regression analysis where, in some specifications, the intensity of national fiscal rules was positively associated with the extent to which (ex ante) targets were met (ex post).

While it is not clear that political setup arrangements play a role in the success of fiscal adjustments, the presence or the build-up of public support seems to enhance their viability. The cross-country evidence yields mixed messages on the role of political factors: lower parliamentary fractionalization and perceptions of greater political stability are to some extent associated with better implementation of plans; on the other hand, implementation of ambitious plans was not associated with more frequent changes in government. What comes out far more clearly from the case studies, however, is the importance of public support. For example, opinion polls ahead of the mid-1990s consolidation in Canada showed broad public support for debt reduction. The authorities took advantage of this to put in place a communication strategy to reinforce support for their adjustment plan. They made the case for fiscal adjustment in the media and explained the rationale for the strategic choice they made in how to attain the adjustment. In Germany, a general shift in the economic policymaking paradigm in the 1980s (against active short-term demand management) and a reformist platform of the left-of-center party in the 2000s helped sustain fiscal adjustment.

\section{Regression-Based Analysis}

Having outlined the broad findings from both the case studies on each of the G7 and the statistical analysis based on the EU sample, we now provide in somewhat greater detail the results of our regression-based analysis of the determinants of deviations of ex post outcomes from ex ante plans ("implementation errors," actual minus planned adjustment, all scaled by GDP) for the EU sample. While the case studies provide in-depth analysis of consolidation attempts in individual G7 countries, here we cast the net wider to cover all the EU countries over the past two decades. Reassuringly, several key messages come through consistently in both the case studies and the statistical analysis.

We focus on episodes of large planned fiscal adjustments over a mediumterm (three-year) horizon. In doing so, we are motivated by the current policy 
context where many countries are preparing multiyear strategies for large fiscal consolidation to bring debt down from historic postcrisis levels. Moreover, adjustments planned over several years may better capture medium-term fiscal policy goals than a one-year plan whose construction and outcomes are likely contaminated by various short-term factors.

Before turning to the results, a few words about the topic of revisions to the initial fiscal position (the "base effect"), which plays an important role in the estimation. Large and unexpected data revisions are a fact of life for many policymakers. In the context of multiyear plans and their implementation, such data revisions, especially to the initial fiscal position, can have a significant effect on adjustment needs and incentives. For illustration purposes, consider a scenario in which the estimated fiscal balance for year $t$ (the starting position for a three-year adjustment plan) is revised upward (that is, unexpectedly improves) by 1 percent of GDP in year $t+1$. Policymakers could respond in several ways to this "news": if they wish to maintain unchanged the originally set fiscal balance target for year $t+3$, they will lower their fiscal effort in the plan's outer years by 1 percent of GDP; but if they seek to preserve the amount of fiscal adjustment envisaged over the life of the plan, they will raise their fiscal balance target for year $t+3$ by 1 percent of GDP. In the former case, the implementation error (defined as actual minus originally planned adjustment) would fall by 1 percent of GDP, whereas in the latter case the implementation error would not be affected by news of the revision.

The mean absolute base effect (for the year $t$ fiscal balance-to-GDP ratio) in our sample of 66 plans is in fact 0.9 percentage points. This is sizable relative to the average planned adjustment, for example (2.5 percent of GDP). On average, about half of the base effect showed up in plan documents within one year. This means that policymakers would have typically had sufficient basis and time to recalibrate their fiscal effort in the plan's outer years, had they wished to do so. Although negative base effects occurred more frequently than positive ones in our sample (three-fifths vs. two-fifths), their average magnitude was similar. In principle, policymakers' response to positive base effects could well differ from their response to negative base effects. The logic underlying this possible asymmetry could be that policymakers may be inclined to "spend" fully a positive revision to the initial deficit (thus, the implementation error would worsen by the amount of the revision), while insufficiently compensating for negative base effects (the implementation error would remain unchanged). This hypothesis, among others, is explored in the regressions shoen in Table 4.

\section{Explanatory Variables and Methodology}

The explanatory variables are the following:

1. Initial fiscal balance, measured by the year $t$ overall balance (in percent of GDP). A larger initial balance (that is, a better starting fiscal position) 
might be expected to be associated with worse implementation of fiscal adjustment plans.

2. Fiscal balance base effect, measured by the ex post revision of the initial overall fiscal balance (in percent of GDP). As discussed above, an upward revision in the initial balance could reduce the need for adjustment effort, thereby possibly worsening implementation.

3. Real GDP growth surprise, measured by the percentage point difference between the cumulative actual and planned growth rates over the threeyear plan horizon (or, equivalently, the percentage point surprise in third-year output). In the absence of an active response by policymakers, the direct effect on the headline fiscal balance would be essentially equal to the automatic stabilizers (that is, approximately the percentage point surprise in third-year output times the share of total expenditure in GDP).

4. Plan ambition, measured by the planned improvement in the fiscal balance between year $t$ and year $t+3$ (in percent of GDP). This explores whether more ambitious plans face greater challenges in implementation.

5. Fiscal rules stringency index, from the database assembled by the European Union's ECFIN Directorate General (see its website for a complete description). The index includes both national rules enshrined in law (which necessitate fiscal correction once fiscal indicators approach or breach certain thresholds) and well-defined supranational rules, such as the EU's Maastricht corrective and dissuasive arms (deficit below 3 percent of GDP and debt below 60 percent of GDP, respectively). The violation of these norms and rules is typically associated with reputational costs, but in some cases also triggers penalties. This explanatory variable helps to explore whether the presence of stringent fiscal rules is associated with better implementation of government plans.

6. Changes in government stability, measured as the annual average share of veto players dropping out of government during the plan horizon, drawn from the World Bank's Database of Political Institutions, 2010 vintage.

7. Parliamentary fractionalization - measured as the probability that two deputies randomly drawn from the legislature will belong to different parties (data drawn from the World Bank's Database of Political Institutions, 2010 vintage). This explores whether a high average level of parliamentary fractionalization over the plan period is associated with weakened ability to implement large/painful fiscal adjustments.

\section{Exploring Asymmetric Effects}

Whether the effect of economic growth surprises works symmetrically (that is, with the same coefficient for both positive and negative growth surprises) is also an interesting question to explore. One might expect, for example, that policymakers could plausibly spend some or all of a positive growth surprise as long as the headline deficit targets are preserved, whereas they might allow the automatic stabilizers to operate fully and even respond with stimulus 
measures to negative growth surprises. (In other words, policymakers might be tempted into procyclical fiscal policy in unexpected boom years but might want to use fiscal policy as a countercyclical tool against unexpected economic downturns.) The behavioral response to growth surprises could also be cast in terms of incentives to undertake "structural" fiscal effort (that is, improvements in the cyclically adjusted fiscal balance) and how these are affected by growth surprises. On the one hand, an unexpected boom might afford greater political space to push through unpopular reforms; on the other hand, the incentive for fiscal adjustment through painful measures might weaken if headline balances are already improving "effortlessly" as a result of positive growth surprises. In some specifications, we explore whether one of these opposing effects prevails.

\section{Estimation Technique}

As in most estimations based upon panels of countries, it is likely that both the dependent variable and the explanatory variables are correlated with unobserved country characteristics. To avoid this problem, we use panel fixed effects (FE) (with robust standard errors). Moreover, one might reasonably be concerned about two-way causation between the dependent variable (unexpected improvement in the headline fiscal balance) and the surprise in economic growth - one of the explanatory variables. To avoid the resulting bias, we use instrumental variable estimation (FE-IV). Specifically, we use the average of other countries' real GDP growth surprises to instrument for the growth surprise of country $i$. The identifying assumption is that the only channel through which other countries' GDP growth surprises are related to the implementation error is through the GDP growth surprise in the country in question; and the implementation error in an individual country has essentially no impact on other countries' GDP growth surprise.

\section{Regression Results}

For the sake of brevity, we present the regression results obtained in our baseline specification (using an automated procedure to drop unduly influential observations). The main results hold in extensive robustness tests presented in the book. The regression results (Table 4) suggest that base effects and, especially, economic growth surprises are the key drivers of implementation errors (deviations of actual from planned fiscal adjustment). Other explanatory variables play a role in some specifications, but are less robust.

The base effect turns out to be significant in all the regressions with its coefficient varying between -0.7 and -1.2 . The large magnitude of this coefficient would seem to suggest that policymakers tend not to adjust their initially set deficit targets by much in the face of revisions to the initial fiscal balance, so that the fiscal consolidation ends up adjusting relative to plan. In other words, if the initial balance is revised upward (downward) by 1 percent of GDP, actual implementation would fall (rise) by three quarters to the full 


\begin{tabular}{|c|c|c|c|c|c|c|c|c|}
\hline \multirow[b]{2}{*}{ Variables } & \multicolumn{4}{|c|}{ Fixed Effects } & \multicolumn{4}{|c|}{ FE Instrumental Variables } \\
\hline & (1) & (2) & (3) & (4) & $(5)$ & (6) & (7) & $(8)$ \\
\hline Overall balance base effect & $\begin{array}{c}-0.70^{* * * *} \\
(0.20)\end{array}$ & & $\begin{array}{c}-0.82 * * * \\
(0.21)\end{array}$ & $\begin{array}{c}-0.72 * * * \\
(0.20)\end{array}$ & $\begin{array}{c}-0.87 * * * \\
(0.20)\end{array}$ & & $\begin{array}{c}-1.22^{* * * *} \\
(0.34)\end{array}$ & $\begin{array}{l}-0.85^{* * * *} \\
(0.18)\end{array}$ \\
\hline Initial fiscal balance & $\begin{array}{c}-0.14 \\
(0.11)\end{array}$ & $\begin{array}{c}-0.13 \\
(0.12)\end{array}$ & $\begin{array}{c}-0.19 \\
(0.11)\end{array}$ & $\begin{array}{c}-0.30^{* *} \\
(0.13)\end{array}$ & $\begin{array}{c}-0.15^{*} \\
(0.091)\end{array}$ & $\begin{array}{c}-0.14 \\
(0.097)\end{array}$ & $\begin{array}{c}-0.30^{* *} \\
(0.12)\end{array}$ & $\begin{array}{c}-0.30^{* * * *} \\
(0.10)\end{array}$ \\
\hline Real GDP growth surprise & $\begin{array}{l}0.38^{* * *} * \\
(0.056)\end{array}$ & $\begin{array}{l}0.37^{* * * *} \\
(0.049)\end{array}$ & & $\begin{array}{l}0.34^{* * * *} \\
(0.048)\end{array}$ & $\begin{array}{l}0.54 * * * \\
(0.092)\end{array}$ & $\begin{array}{l}0.52 * * * \\
(0.090)\end{array}$ & & $\begin{array}{l}0.45^{* * * *} \\
(0.064)\end{array}$ \\
\hline Plan ambition & $\begin{array}{c}-0.0044 \\
(0.19)\end{array}$ & $\begin{array}{c}0.033 \\
(0.21)\end{array}$ & $\begin{array}{c}-0.076 \\
(0.19)\end{array}$ & $\begin{array}{c}-0.26 \\
(0.18)\end{array}$ & $\begin{array}{c}0.11 \\
(0.16)\end{array}$ & $\begin{array}{c}0.14 \\
(0.16)\end{array}$ & $\begin{array}{c}-0.16 \\
(0.20)\end{array}$ & $\begin{array}{c}-0.15 \\
(0.15)\end{array}$ \\
\hline Positive overall balance base effect & & $\begin{array}{c}-1.64 * * * \\
(0.47)\end{array}$ & & & & $\begin{array}{c}-1.69 * * * \\
(0.47)\end{array}$ & & \\
\hline Negative overall balance base effect & & $\begin{array}{c}-0.46^{* *} \\
(0.18)\end{array}$ & & & & $\begin{array}{c}-0.64 * * \\
(0.25)\end{array}$ & & \\
\hline Positive growth surprise & & & $\begin{array}{c}0.21 * * \\
(0.090)\end{array}$ & & & & $\begin{array}{c}-0.087 \\
(0.30)\end{array}$ & \\
\hline Negative growth surprise & & & $\begin{array}{l}0.48^{* * * *} \\
(0.066)\end{array}$ & & & & $\begin{array}{l}0.82 * * * \\
(0.23)\end{array}$ & \\
\hline Fiscal rule strength & & & & $\begin{array}{c}0.41^{*} \\
(0.23)\end{array}$ & & & & $\begin{array}{l}0.38^{* *} \\
(0.16)\end{array}$ \\
\hline Change in government stability & & & & $\begin{array}{l}2.68^{* * *} \\
(0.82)\end{array}$ & & & & $\begin{array}{l}2.25^{* * * *} \\
(0.70)\end{array}$ \\
\hline Parliamentary fractionalization & & & & $\begin{array}{c}-0.47 \\
(2.64)\end{array}$ & & & & $\begin{array}{c}-1.18 \\
(1.67)\end{array}$ \\
\hline Observations & 58 & 58 & 58 & 57 & 58 & 58 & 58 & 57 \\
\hline$R$-squared & 0.58 & 0.61 & 0.60 & 0.71 & 0.50 & 0.53 & 0.44 & 0.66 \\
\hline
\end{tabular}

\footnotetext{
Note: The influential observations to be dropped were identified using the DFBETA procedure in STATA.

Robust standard errors in parentheses
}

$* * * p<0.01, * * p<0.05, * p<0.1$ 
amount of the revision. In the latter case, the null hypothesis that policymakers stick to the original overall balance target despite data revisions to the starting balance cannot be rejected. Note that the previous interpretation implicitly assumes that the coefficient is symmetric for positive and negative base effects, an assumption that we probe further ahead.

For the economic growth surprise, the coefficient is $0.3-0.4$ with FE and 0.4-0.5 with FE-IV. This means that a 1 percentage point increase in the cumulative three-year growth surprise leads to an increase in the implementation error in the range of $0.3-0.5$ percent of GDP. This is consistent with an average government size of about 40 percent of GDP in our sample, and an approximately unit elasticity of revenues and zero elasticity of expenditures (common simplifying working assumptions among practitioners) with respect to GDP. Later, we investigate if the coefficient is similar in the case of positive and negative surprises. Turning to the difference between the size of the coefficients across FE and FE-IV, the smaller FE coefficient is consistent with the downward bias that would arise from reverse causality, and the magnitude of the shift suggests that instrumenting for it is important.

The coefficient on initial fiscal balance varies between -0.1 and -0.3 and, although not consistently significant, has an intuitive interpretation: when policymakers face higher initial deficits (as seen at the time of the plan's inception) they respond with extra effort to reduce plan implementation errors. On average, this implies lower implementation errors by 0.1-0.3 percentage point of GDP for each extra 1 percent of GDP in the initial overall deficit.

The lack of significance of other regressors also has important implications. That plan ambition turns out to be an insignificant predictor for implementation suggests that deviations of outcomes from plans are-on average, controlling for other determinants - similar for more ambitious fiscal adjustment plans as they are for less ambitious plans.

Allowing for different coefficients for positive and negative base effects (column 2), we find the absolute value of the coefficient on positive (favorable) base effects to be significantly higher than on negative ones. On average, a 1 percent of GDP positive base effect, other things equal, worsens plan implementation by 1 percent of GDP or more, whereas a 1 percent of GDP negative base effect improves implementation by 0.5 percent of GDP. In other words, if the initial fiscal balance is found to be better than originally estimated when the plan was drawn up, the fiscal balance outcome at the end of the three years is, at best, unchanged; whereas if the initial fiscal balance is revised to be, say, 1 percent of GDP worse than estimated when the plan was drawn up, the deficit at the end of the three years is only 0.5 percent of GDP worse than would otherwise have been the case. These results lend some support to the hypothesis that a favorable surprise about the initial fiscal position likely induces further fiscal laxity to a greater extent than an unfavorable surprise induces additional fiscal austerity.

There is also evidence of asymmetry in the response to positive and negative growth surprises (column 3). The estimates suggest that policymakers 
do not let the automatic stabilizers operate fully in response to positive growth surprises (a 1 percentage point positive surprise in output by the end of the third year is associated only with a 0.2 percentage point of GDP improvement in the fiscal balance). When growth surprises on the negative side, however, the headline fiscal balance deviation from plans worsens by a significantly larger 0.5 percentage point of GDP, letting the automatic stabilizers operate fully. While the magnitude of the coefficients is not robust to changes in specification, the fiscal slippage is consistently greater for negative growth surprises than the fiscal gain is for positive growth surprises.

Regarding the potential role of institutional and political variables, we find mixed results. In Table 4, national fiscal rules intensity and the change in government stability are statistically significant at the conventional levels. The degree of parliamentary fractionalization is not significant in Table 4, though it is in other specifications reported in the book. Specifically, we find that a one-point increase in the fiscal rules stringency index (or a onestandard-deviation increase that would take us from Hungary to Sweden), improves the implementation error by 0.4 percent of GDP (column 4). For changes in government stability, the results are also significant. If the share of veto players dropping out were increased from 0 to 20 percent, plan implementation would improve by $0.3-0.4$ percent of GDP. For parliamentary fractionalization, the coefficient is not statistically significant in the specification reported here.

\section{Implications for Planned Fiscal Adjustments}

The findings from the individual G7 country case studies as well as from the cross-country statistical analysis for the EU country sample have several implications for the design and implementation of fiscal adjustment plans in the years ahead. Those implications include issues related to the design of the adjustment plans, such as the need to prepare for surprises/shocks and the importance of strong monitoring and accountability of fiscal targets. In addition, the experience with past adjustment plans calls for underpinning the fiscal efforts through appropriate structural reforms and the build-up of public support through communication strategies and enhanced public debate.

\section{Spelling Out How Policies Will Respond to Shocks}

As seen above, shocks, especially to economic growth, often derail fiscal adjustment. Beyond the need for realistic macroeconomic assumptions, plans thus ought to explicitly incorporate mechanisms to deal with such shocks, permitting some flexibility while credibly preserving the mediumterm consolidation objectives. Examples of helpful mechanisms include:

- Multiyear spending limits. To anchor the consolidation path, plans should include binding and well-defined ceilings for expenditures and their 
subcomponents, and would preferably be endorsed not just by the government but also by parliament. The ceilings could exclude items that are cyclical (for example, unemployment benefits), nondiscretionary (for example, interest payments), or fiscally neutral (for example, EU-funded projects).

- Cyclically adjusted targets would let the automatic stabilizers operate in response to cyclical fluctuations. To ensure credibility, the methods used to adjust the fiscal variables for the cycle should be subject to outside scrutiny.

\section{Monitoring and Accountability}

Implementation of plans should be supported by reliable and timely information. Targets need to be based on sound information on the initial state of public finances. Any revisions to the initial position should lead to fine-tuning the adjustment path while keeping the medium-term targets unchanged if possible. Fiscal councils and peer-monitoring processes can enhance accountability in implementing adjustment plans.

\section{Composition of Fiscal Adjustment}

The revenue-expenditure mix of fiscal consolidation plans needs to reflect country-specific societal preferences and structural fiscal characteristics. Consistent with the large size of the state in many advanced economies and expenditure pressures in pensions and, especially, health care, the bulk of adjustment measures going forward is likely to be on expenditures. Nevertheless, in light of the magnitude of needed adjustments and the implementation record of past plans, where revenue increases partly compensated for expenditure overruns, it would seem desirable to redouble monitoring efforts and enhance institutional mechanisms to ensure that expenditure ceilings are adhered to. It would likewise be prudent to prepare additional high-quality measures and reforms on the revenue side, to be deployed in the event of expenditure overruns. Moreover, in an interesting rejoinder with past studies on large fiscal adjustments based upon ex post data, our findings lead us to a more benign perspective regarding so-called "revenue-based adjustments". Indeed, when revenue-based adjustments are grounded in real reforms, they have better chances of being durable than one might infer from experiences (as in the traditional literature) involving revenue increases that stemmed from temporary booms in output, profits, and asset prices.

\section{Structural Reforms}

Structural reforms are needed to underpin successful implementation of large fiscal adjustment plans. For many advanced economies, these would sensibly include measures to reduce not only the size of the public administration and 
the social welfare system, but also the thorniest sources of spending pressures - those from pension and, especially, health entitlements.

\section{Building Public Support}

Public support for fiscal adjustment was a key determinant of governments' ability to meet ambitious fiscal consolidation objectives. Thus, a priority going forward will be to build public support through communication campaigns. These would aim at educating the public about the rationale and the scale of the needed fiscal challenges, and explaining what can reasonably be achieved through reforms without overburdening taxpayers or unduly curtailing necessary public services.

\section{REFERENCES}

Abbas, S.M. Ali, N. Belhocine, A. El-Ganainy, and M. Horton, 2011, "Historical Patterns and Dynamics of Public Debt: Evidence from a New Database," IMF Economic Review, Vol. 59, No. 4, pp. 717-42.

Alesina, Alberto, and Roberto Perotti, 1995, "Fiscal Expansions and Adjustments in OECD Countries," Economic Policy, No. 21, pp. 205-40.

Alesina, Alberto, and Silvia Ardagna, 1998, "Tales of Fiscal Adjustment," Economic Policy, Vol. 13, No. 27, pp. 489-545.

_ 2009, "Large Changes in Fiscal Policy: Taxes Versus Spending," NBER Working Paper 15439.

Giavazzi, Francesco, Tullio Jappelli, and Marco Pagano, 2000, "Searching for NonLinear Effects of Fiscal Policy: Evidence from Industrial and Developing Countries," European Economic Review, Vol. 44, No. 7, pp. 1259-89.

Gupta, Sanjeev, Emanuele Baldacci, Benedict Clements, and Erwin R. Tiongson, 2005, "What Sustains Fiscal Consolidations in Emerging Market Countries?" International Journal of Finance and Economics, Vol. 10, No. 4, pp. 307-21.

International Monetary Fund (IMF), 2010 World Economic Outlook, World Economic and Financial Surveys (Washington, October).

von Hagen, Jürgen, Andrew H. Hallett, and Rolf Strauch, 2001, "Budgetary Consolidation in the EMU," EC Economic Papers. 